\title{
ALKALI TREATMENT ON SUGARCANE BAGASSE TO IMPROVE PROPERTIES OF GREEN COMPOSITES OF SUGARCANE BAGASSE FIBERS-POLYPROPYLENE
}

\author{
Juliana Anggono*)1, Niko Riza Habibi ${ }^{2}$, dan Suwandi Sugondo ${ }^{*}$ \\ *) Mechanical Engineering Department - Faculty of Industrial Technology \\ Petra Christian University \\ Jalan Siwalankerto 121-131 Surabaya 60236 \\ Indonesia
}

\begin{abstract}
This work evaluates the improved performance of sugarcane bagasse fibers-polypropylene (PP) composites as a result of alkali treatment done on sugarcane bagasse as reinforcing fibers. Alkali solution of $10 \% \mathrm{NaOH}$ with a temperature of $60-70^{\circ} \mathrm{C}$ was used to soak the bagasse for 2-6 hours. Hot pressed samples were prepared from a mixture of sugarcane bagasse fibers and PP with fibers/PP weight ratios of 20/80, 25/75, and 30/70. Hot pressed samples using untreated bagasse fibers were also produced for a comparison. Tensile test was performed to all samples and the fracture surface from tensile test samples were observed using scanning electron microscopy (SEM) to study how the presence of reinforcement in PP matrix and its alkali treatment influence the strengthening and failure characteristics of the composites. The alkali treatment carried out resulted in a relevant increase of tensile strength of the composite to 229,29 $\mathrm{MPa}$ at 20/80 fibers/PP weight ratio or an increase of $43 \%$ comparing to the composite samples which their fibers were untreated with alkali. The tensile strength of the composite with a 25/75 fibers/PP weight ratio increases to $290,30 \mathrm{MPa}$ and decreases to $214,17 \mathrm{MPa}$ as the fibers/PP weight ratio increases to 30/70. Microstructural study using SEM shows a different outlook on the fiber's surface after alkali treatment which the treatment caused the elimination of the impurities, waxy materials, lignin as well as hemicellulose, which is responsible for an easy deformation of the cellular networks. Alkali treated-sugarcane bagasse gives the best reinforcement for composites after 2 hours of treatment which resulted in the excellent fiberresin bonding.
\end{abstract}

Keywords: sugarcane bagasse, alkali treatment, fiber-resin bonding

\section{INTRODUCTION}

The use of green composites for engineering applications has gained high attention from industries in recent years as their potential to reduce waste from non-degradable synthetic materials and their carbon footprint. These composites using agro-fibers as reinforcement of thermoplastic materials are attractive to the automotive industry for light weighting of components (such as for automobile interiors) while maintaining strength and costcompetitiveness, leading to improved fuel efficiency as well as to satisfy the public demand for 'green cars'. ${ }^{[1,2]}$ Natural fiber composites are also suitable materials to make panels, ceilings, blocks, and partition boards to substitute wood, flooring tiles, etc. in building and construction industry. In comparison with synthetic fibers like glass and carbon, these natural fibers are gaining importance due to its many advantages, such as environment-friendly, reduced greenhouse gas emissions, low energy consumption, low cost, low density, and acceptable

\footnotetext{
${ }^{1}$ Corresponding author, email: julianaa@petra.ac.id

${ }^{2}$ Alumni of Mechanical Engineering Department of Petra Christian University
} 
specific strength properties. ${ }^{[3-6]}$ Indonesia has abundant availability of natural fibres such as pineapple, ramie, coir, bamboo, banana, and sugarcane. Their use can provide value added novel applications of natural fibers based composites and at the end it gives social benefits and major income to communities who cultivate them. This work focused on the potential of waste fibers from sugarcane named bagasse when used as reinforcement in polypropylene matrix. Bagasse is a fibrous residue and about $30 \%$ that remains in a sugarcane mill after crushing the sugarcane stalk and extracting of its juice. ${ }^{[7]}$ It contains short fibers (Figure 1) and consists of water, and small amounts of soluble solids. ${ }^{[8,9]}$ Contribution percentage of each of these components varies according to the variety, maturity, method of harvesting and the efficiency of the crushing plant. The bagasse, thus, produced after juice extraction poses a disposal problem and it is one of the largest agriculture residues in the world. Bagasse is mainly used as a burning raw material (85\%) in sugarcane mill furnaces. ${ }^{[9]}$ However the efficiency of the burning process is low due to low caloric power of bagasse. The excess of bagasse is deposited on empty field altering the landscape. Therefore its existence presents a serious environmental problem which many researchers have performed research work to develop technology, procedure or method that may help to exploit their efficient use. Studies on the impacts, performances and applications of Sugar Cane Bagasse in its original condition; transformed forms; treated with various chemicals and/or processes $^{[10-14]}$; in combination with materials of distinct properties ${ }^{[15-19]}$, and manipulation of manufacturing methodologies ${ }^{[20]}$ have been explored and reviewed. This paper focused on the investigation to develop bagasse fiber reinforced composite material with $20 \mathrm{wt} \%, 25 \mathrm{wt} \%$, and $30 \mathrm{wt} \%$ of bagasse fiber mixed in polypropylene matrix. On the basis of previous works which alkali treatment using $\mathrm{NaOH}$ has been used to modify other natural fibers' surface, ${ }^{[21]}$ the same treatment was employed to bagasse fibers in this work. Their surface adhesive bonding to polypropylene resin or their reinforcement capacity to obtain the maximum strength was investigated.

\section{EXPERIMENTAL PROCEDURES}

\section{(1) Materials Preparation}

The experiment was initiated from the preparation of the sugarcane bagasse (Figure 1a). The bagasse contains of bacteria which can cause unpleasant smell. To remove that unpleasant smell, the bagasse was submerged in ethanol of $90 \%$ for 1 hour and then they were dried up in air in room temperature for about 6 hours before going to an oven drying at temperature of $200^{\circ} \mathrm{C}$ for 30 seconds. Figure $1 \mathrm{~b}$ shows dried bagasse fibers after oven drying. A chemical treatment was performed on the bagasse by submerging the fibers in $300 \mathrm{ml} \mathrm{10 \%} \mathrm{NaOH}$ for 2, 4, and 6 hours at temperature of $60-70^{\circ} \mathrm{C}$. Then they were rinsed with distilled water to cleanse them from $\mathrm{NaOH}$ excess on the surface then followed by drying up in an oven at temperature of $200^{\circ} \mathrm{C}$ for 30 seconds. Figure 1c shows bagasse fibers after alkali treatment. The fibers were then wrapped in aluminum foil to prevent it from moisture sorption from surrounding air and moist. 


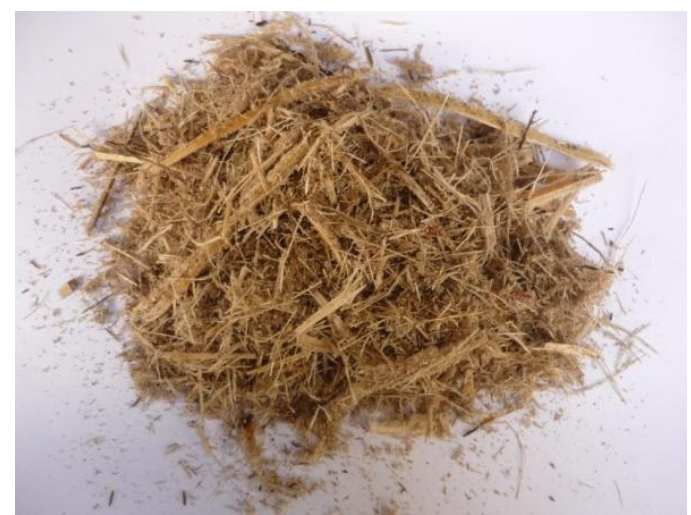

a)

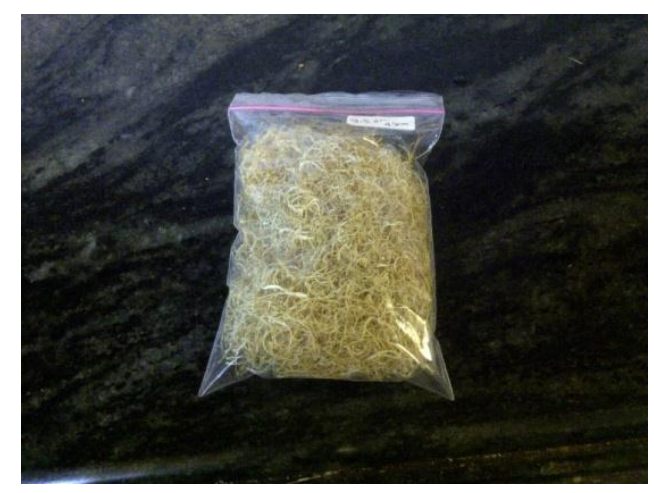

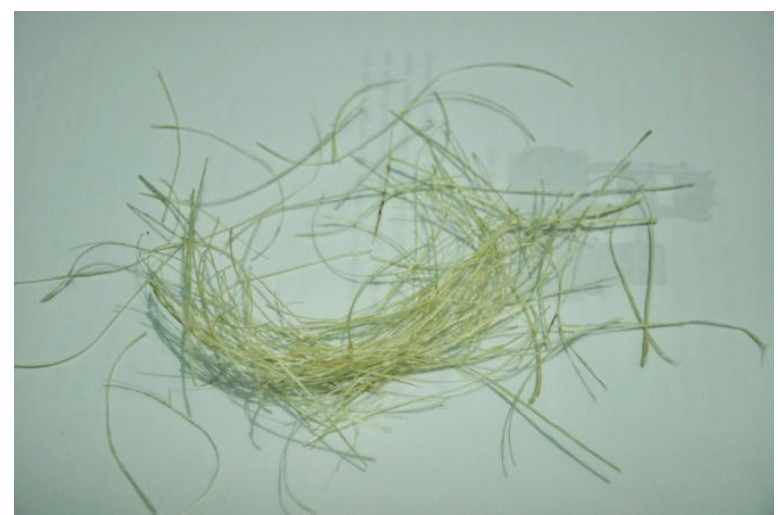

b)

c)

Figure 1 Bagasse fibers a) its original form, b) dried fibers after alcohol cleaning, and c) dried fibers after alkali treatment

Polypropylene (PP) used in this research was in fibers form as shown in Figure 2. The PP fibers were obtained from PT. Classic Prima Carpet Industries which use the fibers as materials to make carpet. Those fibers were cut to obtain a size of $1 \mathrm{~mm}$ in length. That size was chosen to ensure that PP fibers can be well mixed with bagasse.

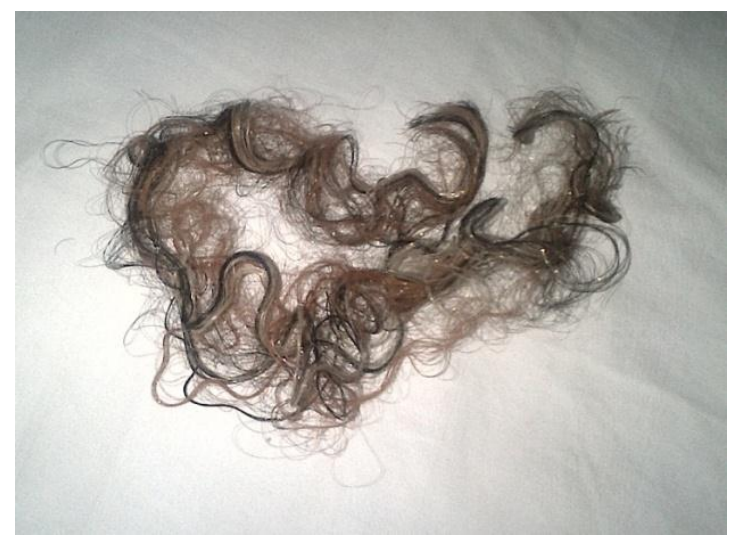

a)

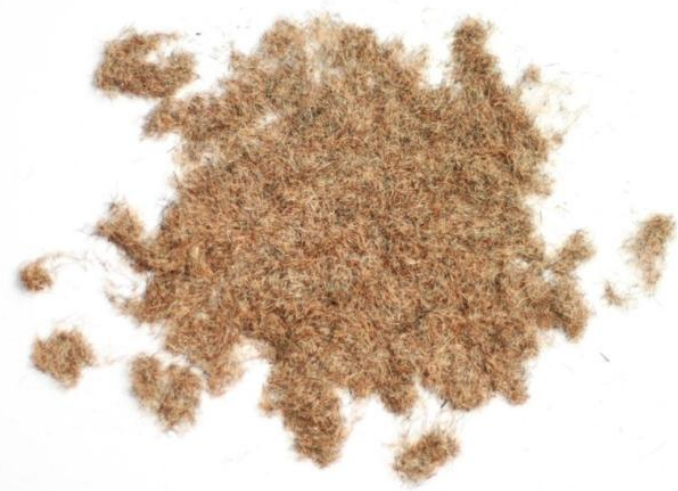

b)

Figure 2 Polypropylene fibers a) in a continuous fiber and b) in $1 \mathrm{~mm}$ length before mixing with bagasse fibres 
Bagasse and PP fibers in different weight ratio (Table 1) were mixed using a mixer of Signora brand, Jumbo Mix type with rotation speed of $17.500 \mathrm{rpm}$ for 3 minutes. Flat type blade was used to prevent the fibers from being fragmented during mixing. A mixture of each different weight ratio of bagasse-PP fibers were hot pressed in a size of $100 \mathrm{~mm}$ x $200 \mathrm{~mm}$ using a pressure of $9800 \mathrm{~Pa}$ which was held for 3 minutes at temperature of $175^{\circ} \mathrm{C}$. The hot-pressed samples were cooled in air for half an hour to let the curing of PP to take place.

\section{(2) Materials Characterisation}

Tensile test specimens were prepared from those hot pressed samples in accordance with ASTM D638M-03 ${ }^{[22]}$ and they were identified as shown in Table 1. Tensile test was performed using Gotech tensile test machine with a capacity of 30 tonnes. To obtain a better understanding of the surface adhesive bonding at the interface of the bagasse-PP fibers as well as to learn the effectiveness of the alkali treatment in modifying fibre surface properties, A Carl Zeiss SEM was used to observe the surface morphology and microstructure of untreated and alkali treated bagasse fibres. Fracture surface of the tensile test specimens were also studied using SEM to investigate the interfacial properties between bagasse fibers and PP matrix.

Table 1. Samples Treatment, Weight Ratio, and Identification

\begin{tabular}{|c|c|c|c|c|}
\hline $\begin{array}{c}\text { Sample } \\
\text { Code }\end{array}$ & $\begin{array}{c}\text { Weight of } \\
\text { Bagasse } \\
\text { Fibers (g) }\end{array}$ & $\begin{array}{l}\text { Weight of } \\
\text { PP fibers } \\
\text { (g) }\end{array}$ & $\begin{array}{c}\text { Bagasse:PP } \\
\text { Weight } \\
\text { Ratio (\%) }\end{array}$ & $\begin{array}{c}\text { Alkali } \\
\text { Treatment }\end{array}$ \\
\hline $\mathrm{A}_{\mathrm{i}}$ & \multirow{4}{*}{4} & \multirow{4}{*}{16} & \multirow{4}{*}{$20 / 80$} & None \\
\hline$\overline{A_{j}}$ & & & & 2 hours \\
\hline$\widehat{A_{k}}$ & & & & 4 hours \\
\hline $\mathrm{A}_{1}$ & & & & 6 hours \\
\hline$\overline{B_{i}}$ & \multirow{4}{*}{5} & \multirow{4}{*}{15} & \multirow{4}{*}{$25 / 75$} & None \\
\hline$\overline{B_{j}}$ & & & & 2 hours \\
\hline $\mathrm{B}_{\mathrm{k}}$ & & & & 4 hours \\
\hline $\mathrm{B}_{1}$ & & & & 6 hours \\
\hline$\overline{C_{i}}$ & \multirow{4}{*}{6} & \multirow{4}{*}{14} & \multirow{4}{*}{$30 / 70$} & None \\
\hline$\overline{C_{j}}$ & & & & 2 hours \\
\hline $\mathrm{C}_{\mathrm{k}}$ & & & & 4 hours \\
\hline $\mathrm{C}_{\mathrm{l}}$ & & & & 6 hours \\
\hline
\end{tabular}

\section{RESULTS AND DISCUSSION}

\section{(1) Thickness Dimension}

The thickness of hot pressed bagasse fibers-PP composites prepared from various bagasse:PP weight ratios and different soaking time in alkali was measured using a caliper. The thickness measurement was shown in Figure 3. The chart indicates that the thickness increment is in accordance with the increase weight of bagasse fiber in the composite and the decrease of 
soaking time of bagasse fiber in $\mathrm{NaOH}$. Adding more bagasse fibers into PP matrix causing the stacking layer of fibers in the composite increases thus it will increase the thickness of the composite. The lowest thickness of $2,17 \mathrm{~mm}$ was obtained in sample $A_{i}$ and the highest thickness was obtained from sample $C_{i}$ with $3,81 \mathrm{~mm}$ thick. Samples with "j", "k", and "l" code (samples with their bagasse fibers were soaked in $\mathrm{NaOH}$ ) had decreased thickness compared with the thickness of samples with " $\mathrm{i}$ " code (their bagasse fibers were not soaked in $\mathrm{NaOH}$ ). Those thickness data inform that the longer time the fibres were soaked in $\mathrm{NaOH}$ the thickness of the composites obtained got decrease. That happened because alkali treatment in $\mathrm{NaOH}$ causing the surface of the bagasse fibers was cleaned by removing hemicellulose and lignin which leads to a decrease in diameter and an increase in fibers crystallinity. ${ }^{[21]}$

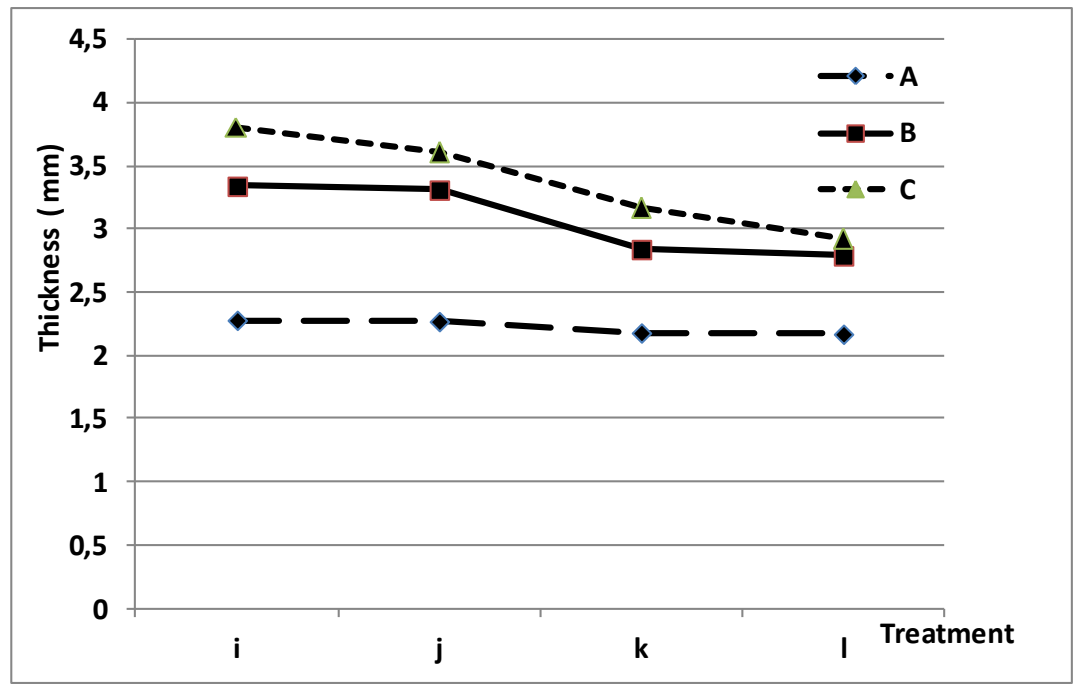

Figure 3 Composite's thickness against baggase:PP weight ratio and bagasse soaking time in $\mathrm{NaOH}$.

\section{(2) Tensile Properties}

Tensile test were performed to all samples of various composition and treatments. The test results were compared to learn the effect of the increase of bagasse to PP weight ratio and soaking time on tensile strength. Figure 4 shows that in comparison with tensile strength of the composite samples $A_{i}, B_{i}$, and $C_{i}$ (using untreated bagasse fibers), the strength of samples $A_{j, k, l}$, $\mathrm{B}_{\mathrm{j}, \mathrm{k}, \mathrm{l}}$, and $\mathrm{C}_{\mathrm{j}, \mathrm{k}, \mathrm{l}}$, was improved as increments of $15-43 \% ; 31-80 \%$; 43-61\% respectively were identified if the bagasse fibers were treated with $\mathrm{NaOH}$. The highest tensile strength was identified in $\mathrm{B}_{\mathrm{j}}$ sample with bagasse:PP weight ratio of 25/75 and its bagasse experienced 2 hours alkali treatment in $\mathrm{NaOH}$. A trend of decrease in tensile strength is shown in the graph in Figure 4 with respect to the soaking time in $\mathrm{NaOH}$ which the lowest strength was identified in samples coded "l" which their bagasse fibers were soaked for 6 hours in $\mathrm{NaOH}$. However this value of strength is still higher $15 \%$ to $43 \%$ compared to samples with untreated bagasse fibers (coded 'i'). Highest tensile strength of the composite was achieved when soaking time of the bagasse in $\mathrm{NaOH}$ was performed for 2 hours. Soaking time more than 2 hours, i.e. 4 and 6 hours caused the tensile strength to decrease. This is relevant with the microstructural observation on the fracture surface area of those samples which will be explained later. Other interesting findings from tensile test data were as the amount of bagasse fibers increases in the composite more than $25 \%$ resulted in the decrease of the composite's tensile strength. Composites samples 
$\mathrm{C}$ which have bagasse fibers of $30 \mathrm{wt} . \%$ experienced a decrease in strength as shown in Figure 4. Similar findings were also identified by Rout et al who studied composites of polyester reinforced with coir fibres. ${ }^{[23]}$

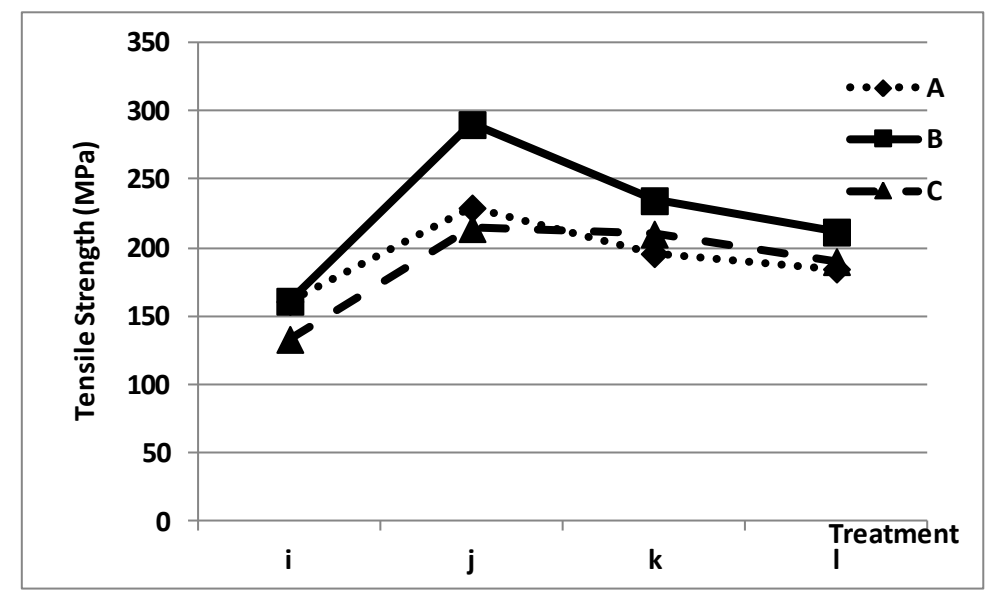

Figure 4 Tensile strength of Bagasse fibers - PP composites in various bagasse: PP weight ratio and soaking time

\section{(3) Microstructural Study}

\section{Sugarcane Fiber Structure}

To confirm the effect of $\mathrm{NaOH}$ treatment on morphological characteristics of bagasse fibers, the samples were studied using SEM. Figure 5 shows that differences are apparent on surface morphology between untreated and treated fibres.

The components of bagasse include cellulose $43.8 \%$, hemicellulose $28.6 \%$, lignin $23.5 \%$, ash $1.3 \%$, and other components $2.8 \%{ }^{[20]}$ Cellulose is a semi crystalline polysaccharide made up of D-glucopyranose units linked together by $\beta$-(1-4)-glucosidic bonds ${ }^{[24]}$ and the large amount of hydroxyl group in cellulose gives natural fiber hydrophilic properties. Therefore when the fibres are used to reinforce hydrophobic matrix, it results in a very poor interface and poor resistance to moisture absorption. ${ }^{[25]}$ Hemicellulose is strongly bound to cellulose fibrils presumably by hydrogen bonds. Hemicellulosic polymers are branched, fully amorphous and have a significantly lower molecular weight than cellulose. Because of its open structure containing many hydroxyl and acetyl groups, hemicellulose is partly soluble in water and hygroscopic ${ }^{[26]}$. Lignins are amorphous, highly complex, mainly aromatic, polymers of phenyl propane units ${ }^{[13]}$ but have the least water sorption of the natural fiber components. ${ }^{[26]}$

Figure 5a shows micrograph of untreated bagasse fibers which a superficial layer is evident. The cellulose microfibrils were still intact with a layer of fatty tissue and sugarcane lignin on the fiber surface. To optimize the interfacial properties between fiber and polymer matrix due to hydrophilic nature of natural fibers, a chemical modifications using $10 \% \mathrm{NaOH}$ solution was used to eliminate lignin and hemicellulose on fibers surface. A significant change in morphological structure of the bagasse fiber occurred after treatment with $\mathrm{NaOH}$ for 2 hours (Figure 5c). Figure 5c, d, e show a highly fibrillated surface with a decrease of fibres diameter or an increase of the surface area due to the cleaning of the bagasse surface from impurities, wax cuticle layer, and hemicellulose structures which begin to dissolve in the solvent due to the 
nature of the alkali-soluble hemicellulose in alkali. The fibrils were starting to separate from each other as shown in Figures $5 \mathrm{~d}$ and $5 \mathrm{e}$ because the lignin, the cementing component, had been removed by the action of the alkaline solution leading to an increase of the surface area and potentially improving the fiber-matrix adhesion in the composite. ${ }^{[21]}$ Alkali treatment also affects the fibers' structure by solubilizing hemicellulose, reducing crystallinity, and increasing the available surface area and its pore volume. Figure 5b shows an illustration of how that treatment acts on the matrix of cellulose, hemicelluloses, and lignin. ${ }^{[27]}$ However if the soaking time in $\mathrm{NaOH}$ was too long, as shown by tensile test that the strength of the composite became lower due to the degradation of cellulose structure. ${ }^{[21]}$

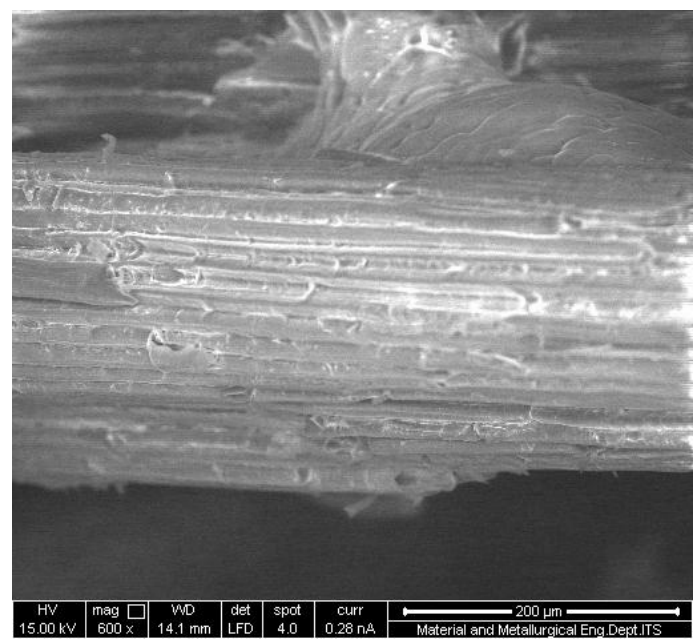

a)

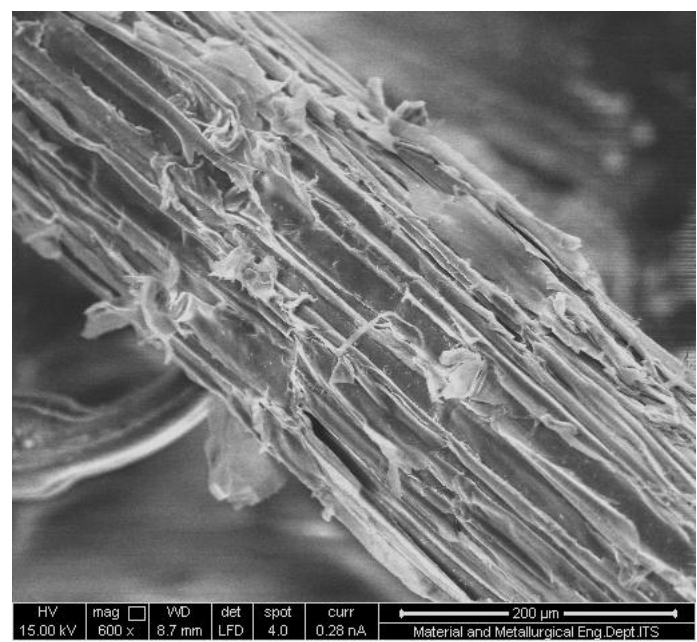

c)

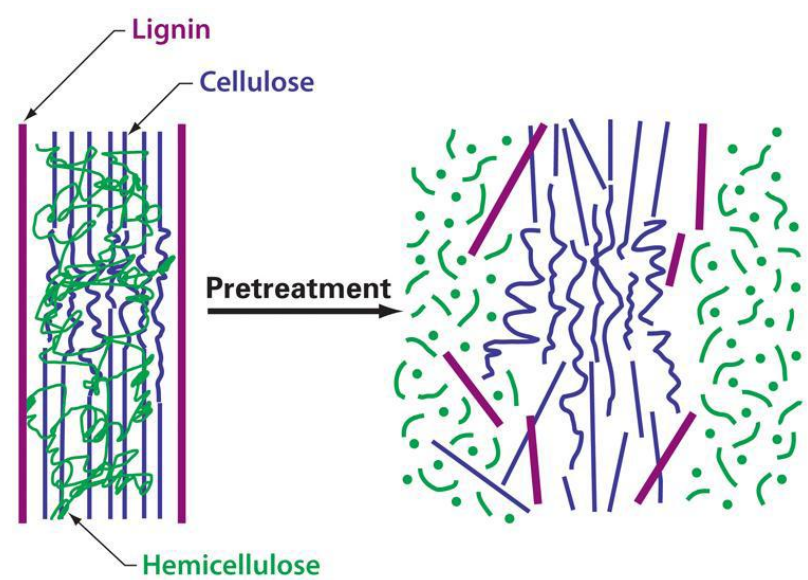

b)

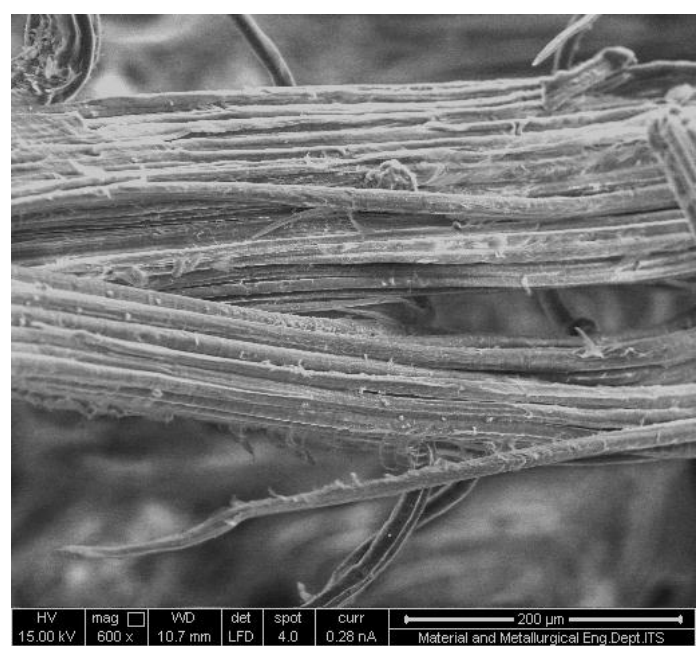

d) 


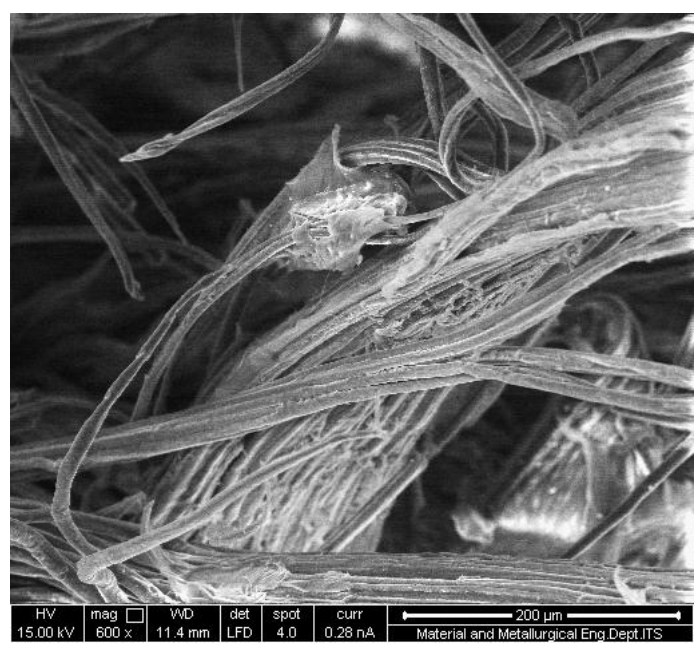

e)

Figure 5 SEM micrographs of bagasse fibers (a) untreated fibers (c) fibers after $\mathrm{NaOH}$ treatmentfor 2 hours (d) fibers after $\mathrm{NaOH}$ treatment for 4 hours (e) fibers after $\mathrm{NaOH}$ treatment for 6 hours; (b) schematic structure of a natural fiber before and after a treatment ${ }^{[27]}$

Structure of Fracture Surface

To support the strength data from tensile test, SEM analysis on the fracture surface was performed. Fracture surface of samples $A_{i}$ and $A_{j}$ was studied to study the change in interfacial properties as an effect of $\mathrm{NaOH}$ treatment of the bagasse fibers. As it has been identified by tensile test that the increase of bagasse fibers more than $25 \mathrm{wt} . \%$ caused the decrease in tensile strength of the composite. Thus the effect of bagasse content on strength needs to be investigated further. Therefore SEM observation was also done on fracture surface of samples $B_{i}$ and $C_{i}$ to get a better understanding on the relationship between the quantity of bagasse fibers in the composite with its strength. SEM images of fracture surface of composite samples $A_{i}$ which the bagasse fibers used were untreated and had the lowest strength (Figure 4) is shown in Figure 6a. This low strength resulted from poor interface adhesion between the bagasse fibers with PP matrix. Fiberpull out is the evidence of that less intimate interfacial contact due to hydrophilicity of bagasse fibers which results in moisture absorption and weak adhesion to PP materials. ${ }^{[9]}$ Low content of bagasse fibers (20 wt.\%) in sampe $A_{i}$ caused the thickness obtained was also low compared to samples $B_{i}$ and $C_{i}$ (Figure 3, 6c, 6d).
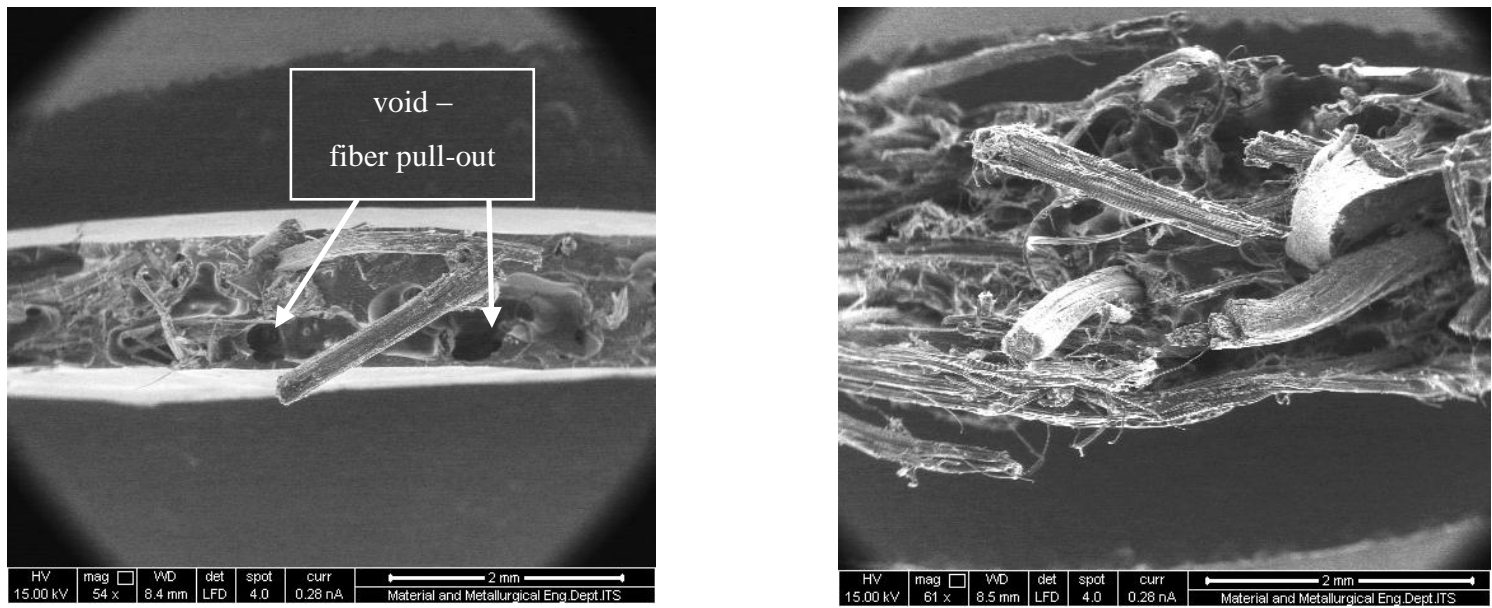
a)

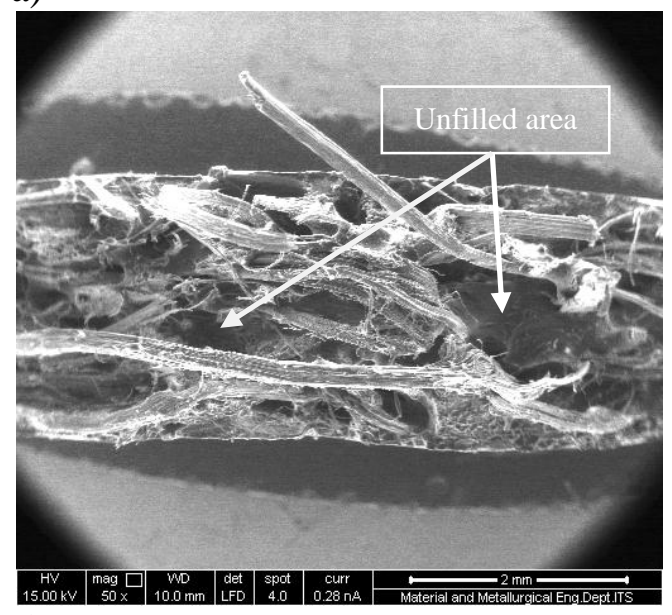

c) b)

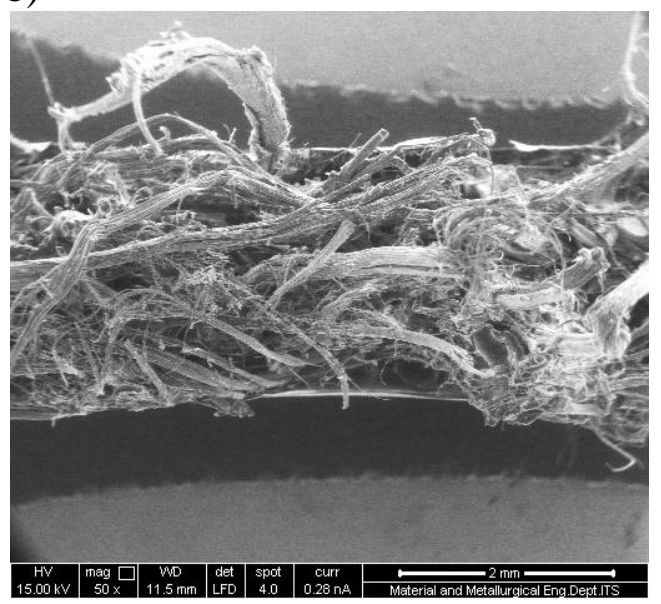

d)

Figure 6 SEM micrographs of samples fracture surface cross section of a) sample $A_{i}$, b) sample $\left.A_{j}, c\right)$ sample $B_{i}$, and d) sample $C_{i}$

Composite's strength made from alkali treated fibers was superior compared to the composite made from untreated fibers. There was $43 \%$ improvement in tensile strength found in sample $\mathrm{A}_{\mathrm{j}}$ $(229,29 \mathrm{MPa})$ compared to sample $\mathrm{A}_{\mathrm{i}}(160,81 \mathrm{MPa})$. Figure $6 \mathrm{~b}$ shows the rough surface of fibers due to the elimination of the external layer of the fibers during alkali treatment therefore it provides better adhesion between fibers and matrix. Splitting of fibers in multiple area was evidence of this improved interface properties.

There is no significant difference between SEM images of fracture surface of sample $A_{i}$ (Figure 6a) and sample $B_{i}$ (Figure $6 c$ ) except from higher bagasse fibers content in sample $B_{i}$. It was observed that there was an empty area which was not filled or wetted by PP resin due to bagasse hydrophilic properties. The strength of sample $\mathrm{B}_{\mathrm{i}}$ is $161,01 \mathrm{MPa}$ which the strength does not change significantly by adding more bagasse fibers from 20 to $25 \mathrm{wt} \%$ unless alkali treatment is applied. The increment of bagasse fibres to $30 \mathrm{wt} \%$ was not a solution to improve composite strength. The strength obtained from tensile test on sample $\mathrm{C}_{\mathrm{i}}(133,11 \mathrm{MPa})$ decreases $21 \%$ compared to the strength of sample Bi when bagasse fibres used was increased to $30 \mathrm{wt}$. $\%$. This happened because of the shortage of PP resin which bonded the bagasse fibers as shown from the SEM micrograph in Figure 6d. Therefore the maximum strength in this work was obtained when the weight ratio of bagasse fibers:PP is $25 / 75$.

\section{CONCLUSION}

1. Increase soaking time of bagasse fibers in $10 \% \mathrm{NaOH}$ solution results in the reduction of composite thickness. A decrease in thickness follows the increase of the amount of bagasse fibers in the composite as well as the increase of soaking time of bagasse in $\mathrm{NaOH}$ solution. The biggest reduction in thickness $(23 \%)$ takes place in sample $\mathrm{C}_{1}$ which the bagasse: PP weight ratio is 30/70 and the bagasse was soaked for 6 hours. The reduction in thickness was due to alkali treatment resulted in the loss of existing pitch surface thus reducing the diameter of fibers.

2. The highest tensile strength $(290.30 \mathrm{MPa})$ was obtained in sample $\mathrm{B}_{\mathrm{j}}$ with bagasse:PP weight ratio of 25/75 and the lowest tensile strength of $133.11 \mathrm{MPa}$ was found with sample $\mathrm{C}_{\mathrm{i}}$. An increase of the amount of bagasse fibers more than $25 \mathrm{wt} \%$ is not a solution to improve tensile strength of the composite. A treatment using $10 \% \mathrm{NaOH}$ with 
a duration of 2 hours performed on bagasse fibers before mixing them with PP fibers was a good way to improve good adhesion between bagasse fibers and PP matrix due to the removal of hemicellulose and lignin which resisted the wetting of PP on the fibers.

\section{ACKNOWLEDGEMENT}

The authors are grateful for the assistance of Is from Material and Metallurgical Engineering Department of Technological Institute of Sepuluh November (ITS) in performing SEM observation.

\section{REFERENCES}

1. S.N. Monteiro, et al., Selection of High Strength Natural Fibers, Revista Matéria, 15(4), 488505 (2011).

2. MERCEDES-BENZ, http://www.mercedes-benz.com.br, Accessed 30 August 2008.

3. N. Chand, P.K. Rohatgi, Natural Fibers And Their Composite, Periodical Experts, Delhi (1994).

4. N. Chand, U.K. Dwivedi, Effect of Coupling Agent On High Stress Abrasive Wear of Chopped Jute/PP Composite, Journal of Wear, 261, 1057 (2006).

5. J. Tong, L. Ren, J. Li, B. Chen, Abrasive Wear Behaviour of Bamboo, Tribol. Int., 28 (5), 323-327 (1995).

6. S. Jain, R. Kumar, U.C. Jindal, Mechanical Behaviour of Bamboo and Bamboo Composites, J. Mat. Sci., 27, 4598-4604 (1992).

7. http://berita.plasa.msn.com/bisnis/okezone/gunakan-ampas-tebu-ptpn-x-hemat-bbm, Accessed 30 December 2013 (in Indonesian Language).

8. Food \& Agricultural Organization: "Production of Agricultural Commodities "FAO (2006).

9. D. Verma, et al., Bagasse Fiber Composites-A Review, J. Mater. Environ. Sci., 3 (6), 10791092 (2012)

10. A. Vazquez, V. A. Dominguez, J. M. Kenny, Bagasse Fiber-Polypropylene Based Composites, Journal of Thermoplastic Composite Materials, 12, 477-497 (1999).

11. J.M.F. Paiva and E. Frollini, Sugarcane Bagasse Reinforced Phenolic and Lignophenolic Composites, Journal of Applied Polymer Science, 83, 880-888 (2002).

12. Zheng Yu-Tao, Cao De-Rong, Wang Dong-Shan, Chen Jiu-Ji; Study On The Interface Modification of Bagasse Fiber and The Mechanical Properties of Its Composite With PVC, Composites: Part A, 38, 20-25 (2007).

13. C.P. da Silva, Tessie Gouvêa da Cruz, Clodoaldo Saron, Sugarcane Bagasse Cellulose/HDPE Composites Obtained By Extrusion, Composites Science and Technology, 69, 214-219 (2009).

14. Martin, J. Puls, B. Saake and A. Schreiber, Effect of Glycerol Preatreatment On Component Recovery and Enzymatic Hydrolysis of Sugarcane Bagasse, Cellulose Chemistry and Technology, 45, 487-494 (2011).

15. S.N. Monteiro, R.J.S. Rodriquez, M.V. De Souza, J.R.M. D'Almeida, Sugar Cane Bagasse Waste as Reinforcement in Low Cost Composites, Advanced Performance Material, 5(3), 183-191 (1998)

16. K. Bilba, M.A. Arsene, A. Quensanga, Sugarcane Bagasse Fiber Reinforced Cement Composites. Part I. Influence of The Botanical Components of Bagasse On The Setting of Bagasse/Cement Composite, Cement Concrete Composite, 25, 91-96 (2003).

17. S. Shibata, Y. Cao, I. Fukumoto, Effect of Bagasse Fiber On The Flexural Properties of Biodegradable Composites, Journal of Polymer Composite, 26, 689-694 (2005). 
18. N.S.M El-Tayeb, Abrasive Wear Performance of Untreated SCF Reinforced Polymer Composite, Journal of Material Processing Technology, 206, 305-314 (2008).

19. J.O. Osarenmwinda and S. I. Abode, Potential of Carbonized Bagasse Filler in Rubber Products, J. Emer. Trends in Eng. Appl. Sci. (JETEAS), 1, 157-160 (2010).

20. S.M. Luz, A.R. Gonçalves, and A.P. Del'Arco, Jr, Mechanical Behavior and Microstructural Analysis of Sugarcane Bagasse Fibers Reinforced Polypropylene Composites, 38, 1455-1461 (2007).

21. M. Esmeraldo, et al., Dwarf-Green Coconut Fibers: A Versatile Natural Renewable Raw Bioresource. Treatment, Morphology, And Physicochemical Properties, BioResources, 5(4), 2478-2501 (2010).

22. American Society for Testing and Materials Standards (2003), ASTM D638M-03 Standard Test Method for Tensile Properties of Plastics.

23. J. Rout, et al., Effects of Coir Fiber Surface Modification in Mechanical Strength of Coir Fiber Polyester Composites (2001) 12 April 2010 <http://proquest.com/scientific〉.

24. R.M. Rowell, R.A. Young, J.K. Rowell, Paper And Composites From Agro-Based Resources, CRC Lewis Publishers, Boca Raton RL (1997).

25. V.A. Alvarez, R.A. Ruscekaite, A. Vazquez, Journal of Composite Material, 37(17), 1575 (2003).

26. T.W. Frederick, W. Norman, Natural Fibers Plastics And Composites, Kluwer Academic Publishers, New York (2004).

27. http://genomicsgtl.energy.gov/biofuels/, Accessed 1 January 2014. 